\title{
Effect of Impaired Lung Function on the Development and Progression of Endobronchial Premalignant Lesions
}

\author{
Vijayvel Jayaprakash ${ }^{1,2,3}$, Gregory M. Loewen ${ }^{4}$, Martin C. Mahoney ${ }^{3,5}$, Samjot Dhillon ${ }^{5}$, \\ Sai Yendamuri ${ }^{6}$, D. Kyle Hogarth ${ }^{7}$, Enrique Machare-Delgado ${ }^{8}$, Ravi J. Menezes ${ }^{9}$, \\ Sandra M. Jacob ${ }^{5}$, Mary E. Reid ${ }^{1,3,5^{*}}$
}

${ }^{1}$ Cancer Prevention and Population Sciences, Roswell Park Cancer Institute, Buffalo, USA; ${ }^{2}$ Department of Dentistry, Roswell Park Cancer Institute, Buffalo, USA; ${ }^{3}$ Department of Social and Preventive Medicine, State University of New York at Buffalo, Buffalo, USA; ${ }^{4}$ Pulmonary Oncology, Sacred Heart Medical Center, Spokane, USA; ${ }^{5}$ Department of Medicine, Roswell Park Cancer Institute, Buffalo, USA; ${ }^{6}$ Department of Thoracic Surgery, Roswell Park Cancer Institute, Buffalo, USA; ${ }^{7}$ Section of Pulmonary and Critical Care Medicine, University of Chicago, Chicago, USA; ${ }^{8}$ School of Medicine, State University of New York at Buffalo, Buffalo, USA; ${ }^{9}$ Department of Medical Imaging, University Health Network, Toronto, Canada.

Email: *mary.reid@roswellpark.org

Received July $27^{\text {th }}, 2012$; revised August $29^{\text {th }}, 2012$; accepted September $11^{\text {th }}, 2012$

\begin{abstract}
Background: Chronic obstructive pulmonary disease (COPD) and the presence of endobronchial premalignant lesions (EPL) are individual risk factors for lung cancer (LC). However, effect of impaired lung function (ILF) on the natural history of EPL has not been explored. Patients and Methods: This study included 217 high-risk participants from a hospital-based LC surveillance cohort who underwent pulmonary function testing followed by bronchoscopy with endobronchial biopsies. Baseline histopathology diagnoses included 91 cases (41.9\%) with squamous metaplasia (SM), 25 $(11.5 \%)$ with squamous dysplasia (SD), $1(0.5 \%)$ with in-situ carcinoma and $5(2.3 \%)$ with invasive LC. Follow-up biopsies were obtained for 69 patients, and $16(23.2 \%)$ patients demonstrated progression to a higher grade lesion. Regression models were used to evaluate the relationship between ILF and EPL. All the models were adjusted for age, gender and tobacco smoking. Results: Patients with $\mathrm{FEV}_{1} \%$ of $<50 \%$ had 4.5 times greater risk of being diagnosed with an EPL [95\% confidence interval: $1.93-10.80$ ] and 8-fold greater risk of SD, compared to patients with FEV1\% $\geq 80$. COPD was associated with 2.7 and 4.8 times greater risk of SM and SD, respectively. The mean time to progression to a higher-grade lesion was shorter in COPD patients compared to patients without COPD (27 versus 50 months, $\mathrm{p}=$ 0.02). Conclusion: Our results indicate that ILF may be a predictor of prevalence and progression of EPLs among patients at high risk of LC. Therefore, spirometry can be a complementary pre-screening tool for identifying patients with EPL who need more intense LC surveillance.
\end{abstract}

Keywords: COPD; Lung Cancer; Premalignant Lesions; Dysplasia; Pulmonary Function Test; Spirometry

\section{Introduction}

Although the mortality rate due to lung cancer (LC) has been steadily declining over the last decade, the overall 5 -year survival rate has remained a dismal $15 \%$ [1]. This poor survival rate can be attributed to the fact that most patients have an advanced disease stage at diagnosis, often limiting the management strategy to palliative options. While it is considered that early detection and treatment can improve the long term survival rate of LC patients [2], the efficacy and cost effectiveness of LC screening in average or low risk populations is questionable [3-5]. Therefore, selective targeted surveillance in high risk patients is currently a more feasible way to de-

"Corresponding author. tect and treat the disease at the earliest stage.

Intra-epithelial lesions, like squamous metaplasia (SM), squamous dysplasia (SD) and carcinoma-in-situ (CIS) have been classified as precursors to invasive squamous cell carcinoma of lung (SCC) [6-9]. Patients with these endobronchial premalignant lesions (EPL) have been shown to be at a much greater risk of developing a squamous cell carcinoma of the lung. Targeted surveillance in such high-risk subgroup will be a more efficient strategy for early detection and chemoprevention. However, the natural history of these EPLs and factors predicting the progression of these lesions are not yet clear.

Chronic obstructive pulmonary disease (COPD) and LC are both respiratory diseases that share similar risk factors and disease mechanisms [10-12]. The "Global 
Initiative for Chronic Obstructive Lung Disease" (GOLD) defines COPD as a disease with progressive airflow limitation, which is not completely reversible [13]. Spirometry is a widely available and inexpensive test for evaluating the airflow limitation and lung function (LF). It has been shown that patients with moderate to severe COPD are at more than 4 fold increased risk of LC, with a significant linear increase in risk with a greater degree of airway obstruction [14-19]. However, the relationship between impaired LF (ILF) and the risk of development and progression of EPLs is less clear. Clarifying any such association will be useful for defining a high risk cohort in need of intense LC surveillance. This study was conducted to examine the association between spirometric LF measurements and EPLs identified via bronchoscopy aided biopsy.

\section{Materials and Methods}

\subsection{Study Population}

The LC Risk Assessment Center at Roswell Park Cancer Institute (RPCI), Buffalo, NY, assesses and manages patients considered to be high risk by virtue of at least two of the following risk factors: $>20$ pack-year history of tobacco use, asbestos-related lung disease, diagnosed chronic obstructive pulmonary disease with a forced expiratory volume in per second (FEV1) $<70 \%$ of predicted, and/or prior aerodigestive or respiratory cancer treated with curative intent with no evidence of disease for at least 6 months prior to enrollment. As a component of the evaluation, the patients undergo spirometry and a computerized tomography (CT) of the chest, followed by combined white light and autofluorescence bronchoscopy with biopsies. Detailed demographic, histologic and clinical history was collected on these patients. This study was approved by the Institutional Review Board at RPCI.

The current analysis includes only high risk patients who had at least one complete spirometric evaluation within the 6 months preceding their baseline bronchoscopic evaluation. Patients who had a history of previous LC treated with a bi-lobectomy or pneumonectomy were excluded. Patients with a previously diagnosed and untreated EPL (either SM, SD or CIS) were also excluded from this analysis. The current analysis includes 217 patients who satisfied all the inclusion criteria. Among these 217 persons, 69 completed a follow-up bronchoscopy with biopsies and were evaluated for changes in the lesions detected at the baseline bronchoscopy.

\subsection{Clinical Exam and Data Collection}

The patients underwent lung function tests using handheld spirometry based on American Thoracic Society (ATS) guidelines [20]. The spirometric measurements included FEV1 and forced vital capacity (FVC). FEV1/ $\mathrm{FVC}$ ratio was calculated using these values. The percentage of predicted value of FEV1 (FEV1\%) and FVC (FVC\%) were calculated based on predicted equation of Crapo et al. [21]. For patients who had more than one spirometry performed within 6 months prior to baseline examination, the spirometry performed closest to the date of diagnosis was considered for this study. Bronchoscopic examination was conducted using the light induced fluorescence endoscopy (LIFE) device (Xillix LIFE-Lung Fluorescence Endoscopy System, Xillix technologies Corp, Richmond, BC, Canada). Lesions identified under white light and/or fluorescent light were biopsied and were histopathologically graded as benign, SM, SD (mild, moderate or severe), CIS and invasive LC (SCC or adenocarcinoma of the lung). The follow-up bronchoscopy was performed on a pre-specified schedule: 6 months to 1 year for patients with SD and 2 to 3 years for patients with SM, unless there was any exacerbation of symptoms warranting intermediary evaluation based on clinical judgment.

\section{Analysis}

For analysis purposes, FEV1\% was stratified into 3 groups: $\geq 80 \%$ (normal), $50 \%$ to $<80 \%$ (mild/moderate impairment) and $<50 \%$ (severe impairment) and FEV1/ FVC was stratified as: $\geq 70 \%$ (normal), $50 \%$ to $<70 \%$ (mildly reduced) and $<50 \%$ (moderately/severely reduced). The GOLD criterion was used to stratify patients as mild, moderate and severe COPD [13]. According to the GOLD criteria, a patient is diagnosed with mild COPD if FEV1/FVC $<70 \%$ and FEV $1 \geq 80 \%$, moderate COPD if FEV $1 / \mathrm{FVC}<70 \%$ and $50 \% \leq \mathrm{FEV} 1 \geq 80 \%$ and severe COPD if FEV1/FVC $<70 \%$ and FEV1 $<50 \%$. The association between ILF and the odds of detecting EPLs was examined by calculating adjusted odds ratio (OR) and $95 \%$ confidence intervals (CI) using unconditional logistic regression. The risk estimates reported here were adjusted for other significant risk factors like age at time of spirometry, gender and pack-years of cigarettes smoked. The highest histopathologic grade lesion for each person determined the final diagnosis for analytic purpose. For example, if a patient had both SM and moderate SD, the final diagnosis for analytic purposes was moderate SD. Due to the limited number of SDs detected, all grades of SD (mild, moderate and severe) were grouped together for this analysis. Similarly, CIS and LC were also grouped together for analysis purposes. For the follow-up analysis, any change to a higher grade lesion on follow-up biopsy was considered as progresssion. The risk of progression for baseline EPLs was evaluated using hazard ratios (HR) based upon Cox regression models. Risk estimates were adjusted for other 
risk factors like age at time of spirometry, gender and pack-years of cigarettes smoked. The statistical package SPSS version 15.0 (SPSS Inc., Chicago, Ill) was used to conduct these analyses.

\section{Results}

The descriptive characteristics of the 353 patients in the overall screening cohort and the 217 participants included in this analysis are presented in Table 1. More than two-thirds of the 217 patients were males and most self-identified as Caucasian. About $93.1 \%$ of the study participants were either former or current smokers and $41.9 \%$ reported a history of asbestos exposure. Based on baseline biopsy, 91 patients (41.9\%) were diagnosed with SM, $12(5.5 \%)$ with mild SD, 10 (4.6\%) with moderate SD, $3(1.4 \%)$ with severe SD and $1(0.5 \%)$ with CIS, 4 $(1.8 \%)$ with SCC and $1(0.5 \%)$ with adenocarcinoma.

Table 2 presents the risk estimates for the identification of EPLs based on categorical measures of FEV1\%, FEV1/FVC values and COPD. The category of most severe FEV $1 \%$ impairment $(<50 \%$ of predicted) was associated with more than 4.5 times greater risk of detecting EPLs, compared to FEV $1 \%$ of $\geq 80 \%$. Results were similar for categories of FEV1/FVC and when SM and SD were individually examined. Significant trends in the risk of EPLs were noted with increasing severity of COPD overall and within categories of lesions. Similar analysis was also performed for linear estimates of FEV $1 \%$ and FEV1/FVC (Figure 1). The results showed a trend for increased risk of detection of EPLs associated with the decreased LF measured by every liter decrease in FEV1 volume and every $10 \%$ decrease in the FEV1/FVC ratio. The risk of detecting EPLs was also analyzed separately for males and females (Table 3). A statistically significant increase in risk associated with the highest category of airflow limitation was observed in both genders. The risk of detecting EPLs in patients with FEV1\% $<50$ was 3.8 times greater in males and 6.5 times greater in females, compared to patients with FEV1\% $>80$.

We analyzed the risk of progression from baseline EPLs based on COPD status at baseline (Figure 2). A total of 69 patients who completed both baseline and follow-up bronchoscopy were included; follow-up bronchoscopy was completed at a median follow-up interval of 13 months (range: 5 to 73 months). The baseline demographic characteristics of the 69 patients were comparable to the overall population of 217 patients (Table 1). In 16 of the 69 patients $(23 \%)$ the baseline lesion progressed to a higher grade, including 11 of $44(25 \%)$ patients with COPD and 5 of $25(20 \%)$ patients without COPD at baseline. The range of time to progression of lesions on these patients was 7 to 73 months. Among these 16 patients, 10 patients had their baseline SM progress (6 to mild SD and 4 to moderate SD), 2 patients

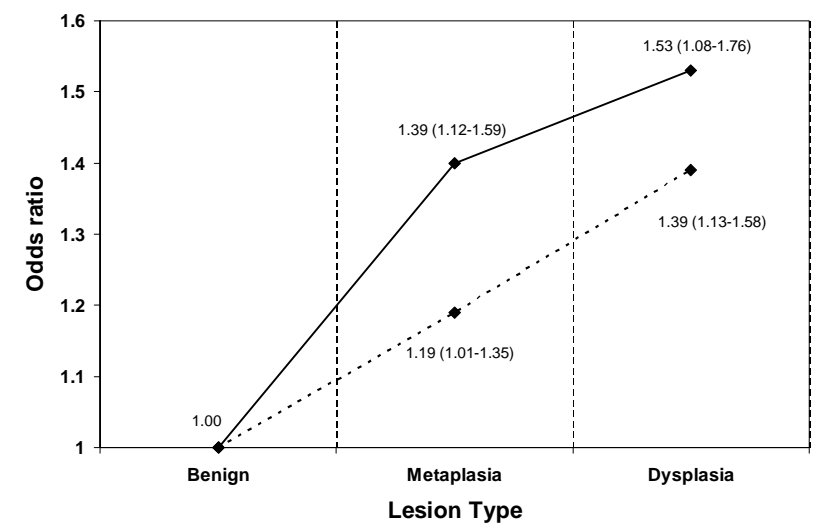

Legend:

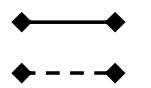

Measured FEV1 — every one litre decrease
FEV1/FVC_- every $10 \%$ decrease

Figure 1. Trend in the odds of detecting premalignant lesions based on linear measures of lung function.
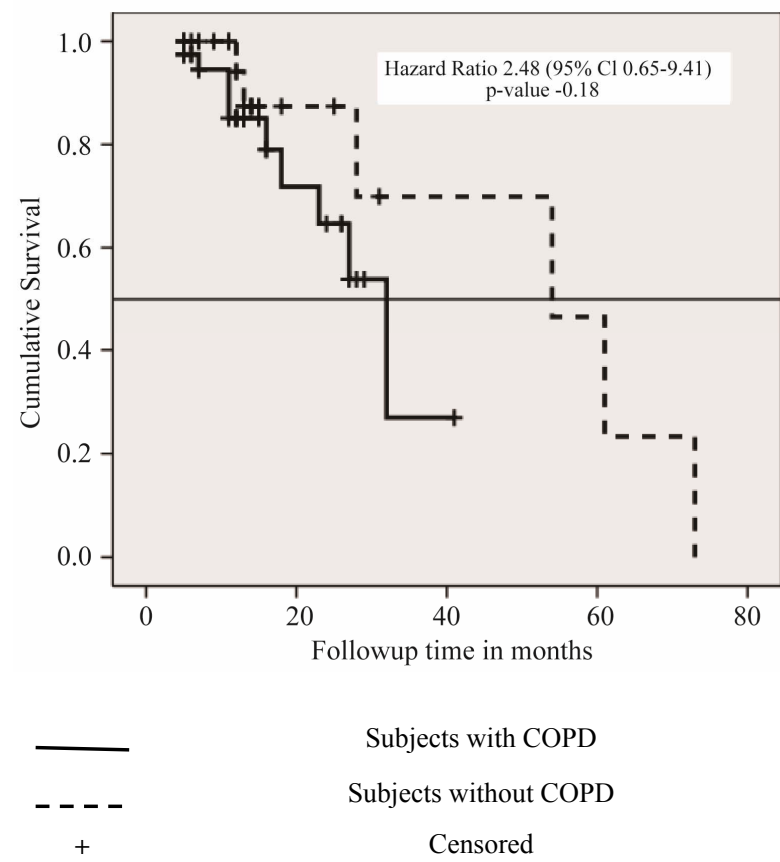

Figure 2. Kaplan-Meier curve to evaluate the difference in progression of baseline premalignant lesions based on COPD status (GOLD criteria).

had their mild SD progress to moderate SD and one patient who had a moderate SD at baseline progressed to severe SD. In 3 other patients who did not have any baseline EPL, 2 were diagnosed with mild SD and 1 patient had moderate SD on follow bronchoscopy. The hazard ratio for the risk of progression was calculated based on a Cox regression model, adjusting for age, gender and pack-years of smoking. The results show that the patients with COPD had a non-statistically significant 2.5 times greater risk of their baseline lesion progressing 
Table 1. Baseline demographic characteristics of all patients who were evaluated for the lung cancer surveillance study.

\begin{tabular}{|c|c|c|c|c|c|c|c|c|c|}
\hline \multicolumn{4}{|c|}{ Characteristics } & \multicolumn{2}{|c|}{$\begin{array}{l}\text { All screening patients } \\
\text { (353 patients) }\end{array}$} & \multicolumn{2}{|c|}{$\begin{array}{c}\text { Patients evaluated with } \\
\text { spirometry followed by } \\
\text { baseline bronchoscopy } \\
\text { (217 patients) }\end{array}$} & \multicolumn{2}{|c|}{$\begin{array}{l}\text { Patients evaluated with } \\
\text { follow-up bronchoscopy } \\
\text { (69 patients) }\end{array}$} \\
\hline \multicolumn{10}{|c|}{ Gender } \\
\hline & & \multicolumn{2}{|c|}{ Female } & \multicolumn{2}{|c|}{$120(34.0)$} & \multicolumn{2}{|c|}{$67(30.9)$} & \multicolumn{2}{|c|}{$22(31.9)$} \\
\hline & & \multicolumn{2}{|r|}{ Male } & \multicolumn{2}{|c|}{$233(66.0)$} & \multicolumn{2}{|c|}{$150(69.1)$} & \multicolumn{2}{|c|}{$46(68.1)$} \\
\hline \multicolumn{10}{|c|}{ Race } \\
\hline & & \multicolumn{2}{|c|}{ Caucasian } & \multicolumn{2}{|c|}{$336(95.2)$} & \multicolumn{2}{|c|}{206 (94.9) } & \multicolumn{2}{|c|}{$66(95.7)$} \\
\hline & & \multicolumn{2}{|c|}{ Black } & \multicolumn{2}{|c|}{$15(4.2)$} & \multicolumn{2}{|c|}{$9(4.1)$} & \multicolumn{2}{|c|}{$2(2.8)$} \\
\hline & & \multicolumn{2}{|c|}{ Other } & \multicolumn{2}{|c|}{$2(0.6)$} & \multicolumn{2}{|c|}{$2(1.0)$} & \multicolumn{2}{|c|}{$1(1.4)$} \\
\hline \multicolumn{10}{|c|}{ Age } \\
\hline & & \multicolumn{2}{|c|}{$<60$ years } & \multicolumn{2}{|c|}{$132(37.4)$} & 80( & 36.9) & & $(43.5)$ \\
\hline & & 60 & 69 years & 125 & $(35.4)$ & 84 & 38.7) & & $(36.2)$ \\
\hline & & & 0 years & & $(27.2)$ & 53 & 24.4) & & $(20.3)$ \\
\hline Smokin & Status & & & & & & & & \\
\hline & & & Never & & $(7.1)$ & 15 & (6.9) & & $(5.8)$ \\
\hline & & & ormer & 221 & $(62.6)$ & 129 & (59.4) & & $(59.4)$ \\
\hline & & & urrent & 106 & $(30.0)$ & 73 & 33.7) & & $(34.8)$ \\
\hline & & Pack-yea & $\mathrm{s}^{1}$ Mean (SD) $\dagger$ & 50. & $(29.5)$ & 50.5 & (27.4) & & $5(23.5)$ \\
\hline Asbestos ex & osure (yes) & & & 140 & $(39.7)$ & 91( & 41.9) & & $(42.1)$ \\
\hline Lung cancer & iistory (yes) & & & 130 & $(36.8)$ & 59 & 27.2) & & $(26.1)$ \\
\hline Reason fo & screening & & & & & & & & \\
\hline Risk fac & rs only ${ }^{*}$ & & & 161 & $(45.6)$ & 100 & (46.1) & & $(47.8)$ \\
\hline Risk factors a & d symptoms* & & & 192 & $(54.4)$ & 117 & (53.9) & & $(52.2)$ \\
\hline $\begin{array}{l}{ }^{\dagger} \text { Among patient } \\
{ }^{* *} \text { Symptoms inc }\end{array}$ & $\begin{array}{l}\text { vith a histor } \\
\text { le hemoptys }\end{array}$ & $\begin{array}{l}\text { f smoking; } \\
\text { persistent cc }\end{array}$ & $\begin{array}{l}\text { "History of hea } \\
\text { ugh or progressi }\end{array}$ & $\begin{array}{l}\text { smoking, a } \\
\text { e dyspnea. }\end{array}$ & sbestos exposur & revious aero- & ligestive cancer a & d clinical di & agnosis of COPD \\
\hline Pulmonary & Normal & All EP & Ls/Cancers ${ }^{1}$ & Squamo & us Metaplasia & $\begin{array}{r}\text { Squam } \\
\text { (aı }\end{array}$ & $\begin{array}{l}\text { ous Dysplasia } \\
\text { y grade) }\end{array}$ & CIS/In & vasive Cancer \\
\hline $\begin{array}{l}\text { Funcuon } \\
\text { Parameter }\end{array}$ & $\begin{array}{l}\mathrm{N}=95 \\
\mathrm{n}(\%)\end{array}$ & $\begin{array}{c}\mathrm{N}=122 \\
\mathrm{n}(\%)\end{array}$ & $\begin{array}{c}\text { Adjusted } \mathrm{OR}^{2} \\
(95 \% \mathrm{CI})\end{array}$ & $\begin{array}{l}\mathrm{N}=91 \\
\mathrm{n}(\%)\end{array}$ & $\begin{array}{l}\text { Adjusted } \mathrm{OR}^{2} \\
(95 \% \mathrm{CI})\end{array}$ & $\begin{array}{c}\mathrm{N}=25 \\
\mathrm{n}(\%)\end{array}$ & $\begin{array}{c}\text { Adjusted } \mathrm{OR}^{2} \\
(95 \% \mathrm{CI})\end{array}$ & $\begin{array}{l}\mathrm{N}=6 \\
\mathrm{n}(\%)\end{array}$ & $\begin{array}{l}\text { Adjusted } \mathrm{OR}^{2} \\
(95 \% \mathrm{CI})\end{array}$ \\
\hline FEV1\% PREI & ICTED & & & & & & & & \\
\hline$\geq 80 \%$ & $32(33.7)$ & $22(18.0)$ & Referent & $18(19.8)$ & Referent & $3(12.0)$ & Referent & $2(33.3)$ & Referent \\
\hline$\geq 50 \%-<80 \%$ & $48(50.5)$ & $58(47.5)$ & $\begin{array}{c}1.58 \\
(0.79-3.18)\end{array}$ & $43(47.3)$ & $\begin{array}{c}1.42 \\
(0.67-3.00)\end{array}$ & $11(44.0)$ & $\begin{array}{c}2.17 \\
(0.54-8.65)\end{array}$ & $3(50.0)$ & $\begin{array}{c}2.09 \\
(0.22-19.76)\end{array}$ \\
\hline$<50 \%$ & $15(15.8)$ & $42(34.4)$ & $\begin{array}{c}4.56 \\
(1.93-10.80)\end{array}$ & $30(33.0)$ & $\begin{array}{c}4.06 \\
(1.62-10.15)\end{array}$ & $11(44.0)$ & $\begin{array}{c}7.95 \\
(1.77-35.67)\end{array}$ & $1(16.7)$ & $\begin{array}{c}2.92 \\
(0.12-68.10)\end{array}$ \\
\hline$P_{\text {trend }}{ }^{3}$ & & & 0.001 & & 0.003 & & 0.005 & & 0.47 \\
\hline
\end{tabular}




\section{Continued}

\begin{tabular}{|c|c|c|c|c|c|c|c|c|c|}
\hline \multicolumn{10}{|l|}{ FEV1/FVC \% } \\
\hline$\geq 70 \%$ & $44(50.6)$ & $38(33.3)$ & Referent & $33(37.9)$ & Referent & $4(19.0)$ & Referent & $1(16.7)$ & Referent \\
\hline$\geq 50 \%-<70 \%$ & $32(36.8)$ & $47(41.2)$ & $\begin{array}{c}1.83 \\
(0.94-3.57)\end{array}$ & $31(35.6)$ & $\begin{array}{c}1.36 \\
(0.66-2.79)\end{array}$ & $11(52.4)$ & $\begin{array}{c}3.35 \\
(0.92-12.15)\end{array}$ & $4(66.7)$ & $\begin{array}{c}9.81 \\
(0.75-128.50)\end{array}$ \\
\hline$<50 \%$ & $11(12.6)$ & $29(25.4)$ & $\begin{array}{c}3.29 \\
(1.36-7.97)\end{array}$ & $23(26.4)$ & $\begin{array}{c}3.11 \\
(1.25-7.72)\end{array}$ & $6(28.6)$ & $\begin{array}{c}5.08 \\
(1.03-25.01)\end{array}$ & $1(16.7)$ & $\begin{array}{c}8.77 \\
(0.35-217.53)\end{array}$ \\
\hline $\mathrm{P}_{\text {trend }}{ }^{3}$ & & & 0.006 & & 0.02 & & 0.04 & & 0.11 \\
\hline \multicolumn{10}{|c|}{ COPD - GOLD CRITERIA ${ }^{4,5}$} \\
\hline $\begin{array}{l}\text { No/Mild } \\
\text { COPD }\end{array}$ & $50(57.5)$ & $41(36.0)$ & Referent & $34(39.1)$ & Referent & $5(23.8)$ & Referent & $2(33.3)$ & Referent \\
\hline $\begin{array}{l}\text { Moderate } \\
\text { COPD }\end{array}$ & $23(29.4)$ & $37(32.5)$ & $\begin{array}{c}2.03 \\
(1.00-4.15)\end{array}$ & $25(28.7)$ & $\begin{array}{c}1.64 \\
(0.76-3.52)\end{array}$ & $9(42.9)$ & $\begin{array}{c}3.27 \\
(0.91-11.83)\end{array}$ & $3(50.0)$ & $\begin{array}{c}4.89 \\
(0.57-42.22)\end{array}$ \\
\hline Severe COPD & $14(16.1)$ & $36(31.6)$ & $\begin{array}{c}3.79 \\
(1.67-8.64)\end{array}$ & $28(32.2)$ & $\begin{array}{c}3.70 \\
(1.57-8.70)\end{array}$ & $7(33.3)$ & $\begin{array}{c}4.84 \\
(1.15-20.43)\end{array}$ & $1(16.7)$ & $\begin{array}{c}2.19 \\
(0.13-37.94)\end{array}$ \\
\hline $\mathrm{P}_{\text {trend }}{ }^{3}$ & & & 0.001 & & 0.003 & & 0.03 & & 0.40 \\
\hline
\end{tabular}

CI, confidence interval; OR, odds ratio; EPL, Endobronchial premalignant lesion; CIS, In-situ carcinoma. ${ }^{1}$ Includes pathological diagnoses- squamous metaplasia, dysplasia, carcinoma in-situ and invasive bronchial carcinoma; ${ }^{2}$ For overall analysis - adjusted for age at pulmonary function test, gender and pack-years of smoking; ${ }^{3} \mathrm{p}$ for trend; ${ }^{4}$ Mild COPD: (FEV1/FVC < 70\% and FEV1 $\geq 80 \%$ ); Moderate COPD: (FEV1/FVC < 70\% and 50\% $\leq$ FEV1 $\geq 80 \%$ ); Severe COPD: (FEV1/FVC $<70 \%$ and FEV1 $<50 \%)$; ${ }^{5}$ Patients who were missing either FEV1 or FVC information were not included in this analysis.

Table 3. Adjusted risk estimates for detection of premalignant bronchial lesions or lung cancers based on the pulmonary function test results, stratified by gender.

\begin{tabular}{|c|c|c|c|c|c|c|}
\hline \multirow[b]{2}{*}{$\begin{array}{l}\text { Pulmonary Function } \\
\text { parameter }\end{array}$} & \multicolumn{3}{|c|}{ MALES } & \multicolumn{3}{|c|}{ FEMALES } \\
\hline & $\begin{array}{c}\text { Normal } \\
(\mathrm{N}=64)^{3} \\
\mathrm{n}(\%)\end{array}$ & $\begin{array}{c}\text { EPLs/Cancers }{ }^{1} \\
(\mathrm{~N}=\mathbf{8 6})^{3} \\
\mathrm{n}(\%)\end{array}$ & $\begin{array}{c}\text { Adjusted OR }{ }^{2} \\
(95 \% \mathrm{CI})\end{array}$ & $\begin{array}{l}\text { Normal } \\
(\mathrm{N}=31)^{3} \\
\mathbf{n}(\%) \\
\end{array}$ & $\begin{array}{c}\text { EPLs/Cancers }{ }^{1} \\
(\mathrm{~N}=36)^{3} \\
\mathrm{n}(\%)\end{array}$ & $\begin{array}{c}\text { Adjusted OR }{ }^{2} \\
(95 \% \mathrm{CI})\end{array}$ \\
\hline \multicolumn{7}{|l|}{ FEV1\% PREDICTED } \\
\hline$\geq 80 \%$ & $22(34.4)$ & $17(19.8)$ & Referent & $10(32.3)$ & $6(16.7)$ & Referent \\
\hline$\geq 50 \%-<80 \%$ & $34(53.1)$ & $43(50.0)$ & $1.43(0.63-3.25)$ & $14(45.2)$ & $14(38.9)$ & $1.52(0.40-5.75)$ \\
\hline$<50 \%$ & $8(12.5)$ & $26(30.2)$ & $3.85(1.34-11.10)$ & $7(22.6)$ & $16(44.4)$ & $6.54(1.42-30.16)$ \\
\hline $\mathrm{P}_{\text {trend }}{ }^{4}$ & & & 0.01 & & & 0.02 \\
\hline \multicolumn{7}{|l|}{ FEV1/FVC \% } \\
\hline$\geq 50 \%-<70 \%$ & $20(33.9)$ & $31(39.2)$ & $1.76(0.79-3.93)$ & $12(42.9)$ & $16(45.7)$ & $1.93(0.56-6.56)$ \\
\hline$<50 \%$ & $7(11.9)$ & $20(25.3)$ & $3.59(1.25-10.33)$ & $4(14.3)$ & $9(25.7)$ & $3.76(0.74-19.04)$ \\
\hline $\mathrm{P}_{\text {trend }}{ }^{4}$ & & & 0.02 & & & 0.10 \\
\hline \multicolumn{7}{|c|}{ COPD_GOLD CRITERIA ${ }^{5}$} \\
\hline No/Mild COPD & $36(61.0)$ & $30(38.0)$ & Referent & $14(50.0)$ & $11(31.4)$ & Referent \\
\hline Moderate COPD & $15(25.4)$ & $25(31.6)$ & $3.01(0.85-4.76)$ & $8(28.6)$ & $12(34.3)$ & $1.98(0.53-7.31)$ \\
\hline Severe COPD & $8(13.6)$ & $24(30.4)$ & $3.78(1.40-10.19)$ & $6(21.4)$ & $12(34.3)$ & $4.54(1.00-20.72)$ \\
\hline $\mathrm{P}_{\text {trend }}{ }^{4}$ & & & 0.007 & & & 0.05 \\
\hline
\end{tabular}

CI, confidence interval; OR, odds ratio; EPL, Endobronchial premalignant lesion; CIS, In-situ carcinoma. ${ }^{1}$ Includes pathological diagnoses- squamous metaplasia, dysplasia, carcinoma in-situ and and invasive bronchial carcinoma; ${ }^{2}$ For overall analysis-adjusted for pack-years of smoking and age at pulmonary function test; ${ }^{3}$ Patients who were missing FEV1 or FVC information were excluded for certain analysis; ${ }^{4} \mathrm{p}$ for trend; ${ }^{5} \mathrm{Mild}$ COPD: (FEV1/FVC $<70 \%$ and FEV1 $\geq 80 \%$ ); Moderate COPD: (FEV1/FVC $<70 \%$ and 50\% $\leq$ FEV1 $\geq 80 \%$ ); Severe COPD: (FEV1/FVC $<70 \%$ and FEV1 $<50 \%$ ). 
to a higher grade [Hazard Ratio 2.48 (95\% CI 0.65 9.41), $\mathrm{p}$-value $=0.18)$ ]. The mean time to progression from a lower grade lesion to a higher grade was 27 months for patients with COPD and 50 months for patients without COPD $(p=0.02)$. The limited sample size precluded more detailed analyses of histologic progresssion.

\section{Discussion}

Several previous studies have reported that ILF and COPD are consistently associated with an increased risk of incident LC [14-19]. ILF has also been shown to be related to LC mortality [14,22,23]. Several mechanisms are proposed to explain the relationship between impaired LF and incident LC. Chronic inflammation of the airway and lung tissue is suggested to be the common pathway in the development of COPD and/or LC [24,25]. Transactivation of genes involved in inflammation and nuclear factor NF- $\mathrm{BB}$ activation can play an important role in development of both LC and COPD [26]. Impaired mucociliary clearance associated with COPD results in decreased clearing of inhaled particulate matter resulting in greater amount of carcinogens getting deposited in the airway [25]. This prolonged contact of carcinogens to lung tissue may be a determinant in the development of LC. This theory might have more credence if the association between ILF and development and progression of EPLs can be demonstrated.

Few studies have examined the relationship between ILF and EPLs. Prindiville et al. failed to identify any increased risk of squamous atypia with greater degree of airflow obstruction [27]. On the other hand, Kennedy et al. reported a high prevalence of SD in patients with COPD who reported at least 40 pack-years of smoking [28]. Both of these studies used sputum cytology to define atypia/SD rather than histopathologic review of biopsy specimens, as was done in our current study. Two other studies have evaluated the prevalence of EPLs using autofluorescence bronchoscopy guided biopsies [7, 29]. While Breuer et al. noted no significant relation between COPD and the prevalence of EPLs $(p=0.40)$, Lam et al. used linear predictors of LF measures and reported that the risk of high-grade EPLs was greater in patients with lower FEV1 volume and FEV1/FVC ratio [29]. Consistent with Lam et al., our study results also show that the patients with lower measures of LF were at a greater risk of EPLs. In addition, the current study also examines the risk of detecting EPLs using categorical measures of LF and demonstrates a "dose-response" relationship with greater level of LF impairment. While Lam et al., noted statistically significant risk estimates for EPLs in men and not in women, our results showed a significant increase in risk among both genders. However, considerable overlap in odds ratios prevents us from evaluating the difference between the two genders.
The relationship between ILF and LC development has previously been shown to be more pronounced with the squamous cell subtype. In a study on patients undergoing lung resection for non-small cell lung cancer (NSCLC), impaired FEV1\% was associated with significant increase in risk for SCC subtype [17]. In another study, Malhotra et al. also reported that impaired FEV1 was associated with greater chance of SCC [30]. We observed that ILF was associated with a 3 to 7 fold increased risk of identifying SM and SD, precursors of SCC.

In addition to demonstrating a greater risk of EPL detection with COPD, our results show that the mean time to progression of the baseline lesions in COPD patients was lesser than the non-COPD patients. Experimental and modeling studies demonstrate total lung deposition of inhaled particulate matter is much greater in patients with obstructive disease compared to healthy individuals, and the deposition enhancement is generally confined to central airways $[31,32]$. This may explain the greater prevalence and risk of progression for EPLs in the setting of airflow obstruction. These patients could be a subgroup that would require a more intense surveillance for LC. However, it should be noted that in our study not all patients had a follow-up biopsy limiting our ability to perform detailed stratified analysis. Also, our study was not powered to assess the risk of detecting invasive LC or to evaluate the risk of progression in detail. In spite of these limitations, our study provides preliminary evidence that impaired lung function may increase the risk of progression of EPLs.

\section{Conclusion}

The current study provides compelling evidence that impaired lung function is associated with a substantially increased risk of developing EPLs. However, larger studies are needed to confirm and expand on these results, and to evaluate progression rates among patients with airflow limitation. Overall, office spirometry can be a noninvasive and inexpensive pre-screening tool to identify patients with EPLs who need active surveillance for LC.

\section{Acknowledgements}

The authors would like to thank Wayne P. Slowik, RRT/RPFT; Sandra J. Michel, RN BSN; and the Stacey Scott Lung Cancer Registry team for their valuable contribution in collecting, cleaning and maintaining clinical information and PFT data.

This study was supported in part by the funding from the Stacey Scott Lung Cancer Registry, Roswell Park Cancer Institute

\section{REFERENCES}

[1] R. Siegel, D. Naishadham and A. Jemal, "Cancer 
Statistics, 2012," CA: A Cancer Journal for Clinicians, Vol. 62, No. 1, 2012, pp. 10-29. doi:10.3322/caac.20138

[2] C. I. Henschke, D. F.Yankelevitz, D. M. Libby, M. W. Pasmantier, J. P. Smith and O. S. Miettinen, "Survival of Patients with Stage I Lung Cancer Detected on CT Screening," New England Journal of Medicine, Vol. 355, No. 17, 2006, pp. 1763-1771. doi:10.1056/NEJMoa060476

[3] P. S. Frame, "Routine Screening for Lung Cancer? Maybe Someday, but Not Yet," Journal of American Medical Association, Vol. 284, No. 15, 2000, pp. 1980-1983. doi:10.1001/jama.284.15.1980

[4] W. D. Travis, E. Brambilla and H. K. Müller-Hermelink, Eds., "Pathology and Genetics: Tumours of the Lung, Pleura, Thymus and Heart,'IARC Press, Lyon, 2004.

[5] P. B. Bach, G. A. Silvestri, M. Hanger and J. R. Jett, "Screening for Lung Cancer: ACCP Evidence-Based Clinical Practice Guidelines," Chest, Vol. 132, No. 3, 2007, pp. 69S-77S.

[6] I. Wistuba, "Genetics of Preneoplasia: Lessons from Lung Cancer," Current Molecular Medicine, Vol. 7, No. 1, 2007, pp. 3-14. doi:10.2174/156652407779940468

[7] R. H. Breuer, A. Pasic, E. F. Smit, E. van Vliet, A. Vonk Noordegraaf, E. J. Risse, P. E. Postmus and T. G. Sutedja, "The Natural Course of Preneoplastic Lesions in Bronchial Epithelium," Clinical Cancer Research, Vol. 11, No. 2, 2005, pp. 537-543.

[8] K. M. Kerr, "Pulmonary Preinvasive Neoplasia," Journal of Clinical Pathology, Vol. 54, No. 4, 2001, pp. 257-271. doi:10.1136/jcp.54.4.257

[9] M. B. Beasley, E. Brambilla and W. D. Travis, "The 2004 World Health Organization Classification of Lung Tumors," Seminars in Roentgenology, Vol. 40, No. 2, 2005, pp. 90-97. doi:10.1053/j.ro.2005.01.001

[10] H. Yao and I. Rahman, "Current Concepts on the Role of Inflammation in COPD and Lung Cancer," Current Opinion in Pharmacology, Vol. 9, No. 4, 2009, pp. 375383. doi:10.1016/j.coph.2009.06.009

[11] A. Punturieri, E. Szabo, T. L. Croxton, S. D. Shapiro, S. M. Dubinett, "Lung Cancer and Chronic Obstructive Pulmonary Disease: Needs and Opportunities for Integrated Research," Journal of the National Cancer Institute, Vol. 101, No. 8, 2009, pp. 554-559. doi:10.1093/jnci/djp023

[12] A. M. Houghton, M. Mouded and S. D. Shapiro, "Common Origins of Lung Cancer and COPD," Nature Medicine, Vol. 14, No. 10, 2008, pp. 1023-1024. doi:10.1038/nm1008-1023

[13] K. F. Rabe, S. Hurd, A. Anzueto, P. J. Barnes, S. A. Buist, P. Calverley, Y. Fukuchi, C. Jenkins, R. Rodriguez-Roisin and C. van Weel, "Global Strategy for the Diagnosis, Management, and Prevention of Chronic Obstructive Pulmonary Disease: GOLD Executive Summary," American Journal of Respiratory and Critical Care Medicine, Vol. 176, No. 6, 2007, pp. 532-555. doi:10.1164/rccm.200703-456SO

[14] D. M. Mannino, S. M. Aguayo, T. L. Petty and S. C. Redd, "Low Lung Function and Incident Lung Cancer in the United States: Data from the First National Health and Nutrition Examination Survey Follow-Up," Archives of Internal Medicine, Vol. 163, No. 12, 2003, pp. 14751480. doi:10.1001/archinte.163.12.1475

[15] M. S. Tockman, N. R. Anthonisen, E. C. Wright and M. G. Donithan, "Airways Obstruction and the Risk for Lung Cancer," Annals of Internal Medicine, Vol. 106, No. 4, 1987, pp. 512-518.

[16] D. M. Skillrud, K. P. Offord and R. D. Miller, "Higher Risk of Lung Cancer in Chronic Obstructive Pulmonary Disease. A Prospective, Matched, Controlled Study," Annals of Internal Medicine, Vol. 105, No. 4, 1986, pp. 503-507.

[17] A. Papi, G. Casoni, G. Caramori, I. Guzzinati, P. Boschetto, F. Ravenna, N. Calia, S. Petruzzelli, L. Corbetta and G. Cavallesco, "COPD Increases the Risk of Squamous Histological Subtype in Smokers Who Develop Non-Small Cell Lung Carcinoma," Thorax, Vol. 59, No. 8, 2004, pp. 679-681. doi:10.1136/thx.2003.018291

[18] A. Nomura, G. N. Stemmermann, P. H. Chyou, E. B. Marcus and A. S. Buist, "Prospective Study of Pulmonary Function and Lung Cancer," The American Review of Respiratory Disease, Vol. 144, No. 2, 1991, pp. 307-311. doi:10.1164/ajrccm/144.2.307

[19] M. P. Purdue, L. Gold, B. Jarvholm, M. C. Alavanja, M. H. Ward and R. Vermeulen, "Impaired Lung Function and Lung Cancer Incidence in a Cohort of Swedish Construction Workers," Thorax, Vol. 62, No. 1, 2007, pp. 51-56. doi:10.1136/thx.2006.064196

[20] B. R. Celli and W. MacNee, "Standards for the Diagnosis and Treatment of Patients with COPD: A Summary of the ATS/ERS Position Paper," European Respiriratory Journal, Vol. 23, No. 6, 2004, pp. 932-946. doi:10.1183/09031936.04.00014304

[21] R. O. Crapo, A. H. Morris and R. M. Gardner, "Reference Spirometric Values Using Techniques and Equipment That Meet ATS Recommendations," The American Review of Respiratory Disease, Vol. 123, No. 6, 1981, pp. 659664.

[22] L. H. Kuller, J. Ockene, E. Meilahn and K. H. Svendsen, "Relation of Forced Expiratory Volume in One Second (FEV1) to Lung Cancer Mortality in the Multiple Risk Factor Intervention Trial (MRFIT)," American Journal of Epidemiology, Vol. 132, No. 2, 1990, pp. 265-274.

[23] L. E. Eberly, J. Ockene, R. Sherwin, L. Yang and L. Kuller, "Pulmonary Function as a Predictor of Lung Cancer Mortality in Continuing Cigarette Smokers and in Quitters," International Journal of Epidemiology, Vol. 32, No. 4, 2003, pp. 592-599. doi:10.1093/ije/dyg177

[24] J. C. Hogg, F. Chu, S. Utokaparch, R. Woods, W. M. Elliott, L. Buzatu, R. M. Cherniack, R. M. Rogers, F. C. Sciurba and H. O. Coxson, "The Nature of Small-Airway Obstruction in Chronic Obstructive Pulmonary Disease," The New England Journal of Medicine, Vol. 350, No. 26, 2004, pp. 2645-2653. doi:10.1056/NEJMoa032158

[25] S. Wasswa-Kintu, W. Q. Gan, S. F. Man, P. D. Pare and D. D. Sin, "Relationship between Reduced Forced Expiratory Volume in One Second and the Risk of Lung Cancer: A Systematic Review and Meta-Analysis," Thorax, 
Vol. 60, No. 7, 2005, pp. 570-575. doi:10.1136/thx.2004.037135

[26] J. S. Brody and A. Spira, "State of the Art. Chronic Obstructive Pulmonary Disease, Inflammation, and Lung Cancer," Proceedings of the American Thoracic Society, Vol. 3, No. 6, 2006, pp. 535-537. doi:10.1513/pats.200603-089MS

[27] S. A. Prindiville, T. Byers, F. R. Hirsch, W. A. Franklin, Y. E. Miller, K. O. Vu, H. J. Wolf, A. E. Baron, K. R. Shroyer and C. Zeng, "Sputum Cytological Atypia as a Predictor of Incident Lung Cancer in a Cohort of Heavy Smokers with Airflow Obstruction," Cancer Epidemiology Biomarkers and Prevention, Vol. 12, No. 10, 2003, pp. 987-993.

[28] T. C. Kennedy, S. P. Proudfoot, W. . Franklin, T. A. Merrick, G. Saccomanno, M. E. Corkill, D. L. Mumma, K. E. Sirgi, Y. E. Miller and P. G. Archer, "Cytopathological Analysis of Sputum in Patients with Airflow Obstruction and Significant Smoking Histories," Cancer Research, Vol. 56, No. 20, 1996, pp. 4673-4678.
[29] S. Lam, J. C. leRiche, Y. Zheng, A. Coldman, C. MacAulay, E. Hawk, G. Kelloff and A. F. Gazdar, "SexRelated Differences in Bronchial Epithelial Changes Associated with Tobacco Smoking," Journal of the National Cancer Institute, Vol. 91, No. 8, 1999, pp. 691696. doi:10.1093/jnci/91.8.691

[30] S. Malhotra, S. Lam, S. F. Man, W. Q. Gan and D. D. Sin, "The Relationship between Stage 1 and 2 Non-Small Cell Lung Cancer and Lung Function in Men and Women," BMC Pulmonary Medicine, Vol. 6, No. 2, 2006.

[31] R. A. Segal, T. B. Martonen, C. S. Kim and M. Shearer, "Computer Simulations of Particle Deposition in the Lungs of Chronic Obstructive Pulmonary Disease Patients," Inhalation Toxicology, Vol. 14, No. 7, 2002, pp. 705-720. doi:10.1080/08958370290084593

[32] C. S. Kim and T. C. Kang, "Comparative Measurement of Lung Deposition of Inhaled Fine Particles in Normal Subjects and Patients with Obstructive Airway Disease," American Journal of Respiratory and Critical Care Medicine, Vol. 155, No. 3, 1997, pp. 899-905. 